\title{
The relationship between circadian disruption and the development of metabolic syndrome and type 2 diabetes
}

REVIEW

\section{Ilia N Karatsoreos}

Department of Integrative Physiology and Neuroscience, Washington State University, Pullman, WA, USA
Correspondence: Ilia N Karatsoreos Department of Integrative Physiology and Neuroscience, Washington State University, 1815 Ferdinand's Lane, Room 205, Pullman, WA 99164, USA $\mathrm{Tel}+\mathrm{I} 5093354829$

Fax + I 5093354650

Email iliak@vetmed.wsu.edu
This article was published in the following Dove Press journal:

ChronoPhysiology and Therapy

5 December 2014

Number of times this article has been viewed
Abstract: Circadian (daily) rhythms are pervasive in nature, and expressed in nearly every behavioral and physiological process. In mammals, circadian rhythms are regulated by the master brain clock in the suprachiasmatic nucleus of the hypothalamus that coordinates the activity of "peripheral" oscillators throughout the brain and body. While much progress has been made in understanding the basic functioning of the circadian clock at the level of genes, molecules, and cells, our understanding of how these clocks interact with complex systems is still in its infancy. Much recent work has focused on the role of circadian clocks in the etiology of disorders as diverse as cancer, diabetes, and obesity. Given the rapid rise in obesity, and the economic costs involved in treating its associated cardiometabolic disorders such as heart disease and diabetes mellitus, understanding the development of obesity and metabolic dysregulation is crucial. Significant epidemiological data indicate a role for circadian rhythms in metabolic disorders. Shift workers have a higher incidence of obesity and diabetes, and laboratory studies in humans show misaligning sleep and the circadian clock leads to hyperinsulinemia. In animal models, body-wide "clock gene" knockout mice are prone to obesity. Further, disrupting the circadian clock by manipulating the light-dark cycle can result in metabolic dysregulation and development of obesity. At the molecular level, elegant studies have shown that targeted disruption of the genetic circadian clock in the pancreas leads to diabetes, highlighting the fact that the circadian clock is directly coupled to metabolism at the cellular level.

Keywords: glucose, metabolism, sleep, rhythms, obesity

\section{Introduction}

Obesity and its comorbid pathologies cardiovascular disease and diabetes mellitus are significant and growing public health problems. Currently, $68 \%$ of US adults have a body mass index $>25 \mathrm{~kg} / \mathrm{m}^{2}$, which is the definition of "overweight", and account for an estimated $10 \%$ of annual health care costs (estimated at $\sim \$ 147$ billion in 2008). ${ }^{1}$ This phenomenon is not restricted to the US. Obesity, and its associated health consequences, is on the rise in several developing countries, demonstrating the global nature of this "epidemic". It is obvious from the epidemiological data that there has been an acceleration of obesity rates worldwide.

Although there are complex and sometimes multiplicative influences on metabolic processes, the causes of obesity fundamentally involve an imbalance between food intake and energy expenditure. While seemingly simplistic, this calculus is at the core of the problem, and similarly at the core of the solution. Obvious solutions would be to decrease caloric intake and increase physical activity, to bring this equation back into balance. However, for many reasons, these solutions may not always be possible. 
In addition, significant gaps still exist in our understanding of body weight control, which continue to limit progress toward the goal of reducing obesity, and thus also reducing associated pathologies such as type 2 diabetes (T2D). New approaches and new ideas are needed to help bridge these gaps, and provide new methods to prevent, treat, or otherwise mitigate the effects of obesity and the metabolic syndrome.

While most people do not usually consider obesity as a "brain disorder", it is important to emphasize that the brain has a central role in the development of obesity. In addition, the brain is also affected by obesity, with peripheral physiological changes directly impacting molecular, cellular, and circuit functions, with implications for behavioral processes. As such, the brain and body are part of the "two-way street" of obesity. Work exploring the brain mechanisms that contribute to obesity, as well as the effects of obesity on central processes, could provide the transformative knowledge to contribute to novel solutions to this epidemic.

Over the past two decades, researchers and clinicians have taken a more integrative approach to the study of numerous disorders, particularly psychiatric and metabolic disease. Several expert reviews in the past year have explored the complex and changing landscape of our understanding of the relationship between circadian rhythms, sleep, and metabolic function..$^{2-6}$ These reviews highlight the integrative explorations, at multiple levels of study, in several species, that have revealed a complex interaction between genetics and environment, showing how both play a role in the development of health problems. I would like to make it clear that by discussing gene-environment interactions I do not mean to invoke the nature versus nurture debate. Instead, when I refer to gene-environment interactions, I imply that both genetic predispositions and/or environmental processes may alter the "normal" trajectory of development, thus leading to altered physiological and behavioral function. In this spirit, this review explores how biological rhythms and external environmental pressures influence metabolic function, and what this may mean for our understanding of obesity and diabetes, and lead to ways to fight this growing disease.

\section{Circadian clocks: a primer}

As previously noted, obesity fundamentally stems from an imbalance between the intake of calories and the expenditure of energy. These processes are strongly controlled by circadian (daily) rhythms, and as such, circadian rhythms may be an important component to measure and manipulate in the study of obesity and diabetes. The circadian timing system controls all physiological and behavioral rhythms, synchronizes them to the external environment, and ensures temporal isolation of incompatible physiological or behavioral processes. ${ }^{7-9}$ This phylogenetically ancient system has many molecular components conserved between diverse species, from Drosophila to mouse to human. ${ }^{10}$ Over the past 25 years, remarkable progress has been made in our investigation of the molecular components of the clock, and in mammals we have gained a good understanding of how the circadian system is organized. A brain clock in the hypothalamic suprachiasmatic nucleus $(\mathrm{SCN})$ is the master clock that synchronizes the organism to the light-dark cycle, and regulates nearly all circadian rhythms. ${ }^{11-15}$ The SCN receives information from the photic environment via the retinohypothalamic tract, which terminates within the SCN to impact cellular function of independent cellular oscillators within this brain structure. Neurons in the SCN have the properties of independent oscillators that are synchronized to each other to provide a cohesive output. These cell autonomous oscillators keep time using a transcription-translation feedback loop that has been well characterized over the past two decades. Briefly, the molecular clock consists of two interlocking coregulatory feedback loops. In the primary loop, CLOCK and Bmall proteins heterodimerize and bind to E-box sequences, mediating transcription of many genes, including members of the Period (Per) family and Cryptochrome (Cry) family. Per and Cry constitute part of the negative arm of the primary loop, and their protein products inhibit CLOCK:Bmall-mediated transcription. A secondary loop complements the first, with Bmall transcription regulated by reverse erythroblastosis virus $\alpha(\mathrm{Rev}$-erb $\alpha)$, retinoic acid receptor-related orphan receptor $\alpha(\operatorname{ROR} \alpha)$, and peroxisome proliferator-activated receptor $\alpha(\operatorname{PPAR} \alpha)$. These further regulate a series of "clock-controlled genes" that impact a variety of cellular functions. ${ }^{16-18}$ Intriguingly, Rev-erb $\alpha$, ROR $\alpha$, and PPAR $\alpha$ play roles in the regulation of lipogenesis, lipid metabolism, and glucose homeostasis. It is clear that there are intimate links between the circadian and metabolic systems at the cell/molecular level as well as at the level of the whole organism. This relationship has led to the hypothesis that disruption of the circadian clock, through either genetic or environmental means, can lead to altered metabolic function, and ultimately to obesity and comorbidities such as diabetes. This review explores the evidence that disrupting the circadian clock can lead to diabetic-like states and the metabolic syndrome.

\section{Circadian rhythms and metabolic function}

Modern industrialized society and the ubiquity of electric lighting have resulted in a fundamental alteration in the relationship 
between our endogenous circadian (daily) clock and the external environment. Thus, our circadian timing system, coordinated by the SCN brain clock, but present in nearly all cells and tissues, is now constantly under pressure from changes in light cycles, behavioral patterns, and new social norms. The American Medical Association has adopted a policy statement on the adverse health effects of nighttime lighting, acknowledging a direct link between disrupted circadian rhythms and cell cycle regulation, DNA damage responses, and metabolism. ${ }^{19}$ How disrupted clocks lead to these problems is an active area of research, but mechanisms remain elusive. A logical place to start this search is at the molecular level: in the genes and molecules that drive the circadian clock or provide links between the circadian clock and metabolic processes.

Many lines of evidence demonstrate that metabolism and circadian rhythms are intimately linked at the physiological and cellular levels. ${ }^{20-26}$ While disruption of the circadian clock is observed in numerous mental and physical disorders, from depression ${ }^{27,28}$ to obesity, ${ }^{22,29}$ it is unclear whether disruption of the circadian clock is a symptom, or a cause, of metabolic dysregulation. Molecular work has begun to address this question by disrupting "clock" genes and observing the effects on metabolism, with marked success in demonstrating that genetic disruption of circadian clocks precipitates the development of obesity. In whole-body CLOCK mutant mice where the circadian clock is altered from birth, development of obesity occurs as a result of a decrease in metabolic rate $(\sim 10 \%)$ and a reorganization of feeding rhythms when measured grossly; specifically $C L O C K$ mice eat more during the light period than do wild-type (WT) mice. ${ }^{30}$ This genetic animal model clearly demonstrates the link between defects in clock function and metabolic dysregulation. However, these large-scale changes in metabolic rate and feeding rhythms need to be elaborated with a cell and molecular investigation. Specifically, links need to be uncovered between the molecular clock and the glucose homeostasis and insulin pathways. In mice, knockout of CLOCK and Bmall leads to impaired glucose tolerance and blunted insulin insensitivity. ${ }^{30-32}$ Mice with mutated Per 2 show increased plasma insulin as well as impaired liver gluconeogenesis. ${ }^{33,34}$ Similarly, Cry1/2 double knockout mice demonstrate a hyperglycemic response to acute feeding and impaired glucose tolerance. ${ }^{35}$ Taken together with the CLOCK knockout mouse, these data demonstrate the primacy of the molecular clock and the regulation of metabolic output at the whole organism and cellular levels.

How is it possible that altering clock gene expression can lead to such marked changes in various systems underlying complex metabolic processes? The molecular components of the circadian clock (eg, core "clock genes" such as CLOCK, Bmall, and the Period and Cryptochrome families of genes) are also found to oscillate in many different brain regions and peripheral tissues. A current model in the field suggests that the SCN sits at the top of a "circadian web", regulating rhythms throughout the brain and body by both direct (eg, neural) and indirect (eg, humoral, behavioral, or metabolic) mechanisms. ${ }^{36,37}$ In this model, the SCN synchronizes "peripheral" oscillators in the body to the light-dark cycle, and to each other, ensuring optimal physiologic function. Thus, while the central clock in the SCN is clearly important in the regulation of metabolic processes, changes in the peripheral clocks may also modulate "local time", and hence local organ function. For instance, disrupting the circadian clock by altering Bmal1 specifically in pancreatic beta cells results in hyperinsulinemia and a diabetic phenotype. ${ }^{21}$ Peripheral tissues throughout the body show rhythms in the expression of not only canonical "clock" genes, but also in thousands of other genes governing myriad cellular processes. Between $10 \%$ and $20 \%$ of genes in the liver transcriptome are rhythmic, ${ }^{38}$ and proteomic analyses estimate circadian rhythmicity in $15 \%-20 \%$ of soluble proteins in the liver. ${ }^{39}$ Groundbreaking bioinformatics work by Eckel-Mahan et al has elegantly demonstrated that there is coherence between the circadian transcriptome, proteome, and metabolome. ${ }^{40,41}$ This makes it clear that the circadian clock is a central regulator of tissue function in the liver, and leads to the prediction that if this clock were to be disrupted, several aspects of tissue function, and hence metabolic function, would be severely impacted.

\section{Molecular links between circadian rhythms and metabolic function: a two-way street}

The circadian clock and metabolism are intimately linked, from the organization of feeding rhythms to cellular metabolism. At the molecular level, defects in clock function have been linked to metabolic dysregulation, particularly to alterations in liver function and glucose metabolism (for a thoughtful review, see Kalsbeek et al). ${ }^{42}$ Groundbreaking work in the previous decade showed the wide reach of circadian rhythms in the regulation of hepatic gene expression and the hepatic proteome. ${ }^{38,39}$ Mechanistic studies further demonstrate that, in mice, knockout of CLOCK and Bmall leads to impaired glucose tolerance and blunted insulin insensitivity. ${ }^{30-32}$ Mice with mutated Per 2 show increased plasma insulin as well as impaired liver gluconeogenesis. ${ }^{33,34}$ Similarly, Cry $1 / 2$ double 
knockout mice demonstrate a hyperglycemic response to acute feeding and impaired glucose tolerance. ${ }^{35}$ At the systems level, elegant work demonstrates the role of the SCN in the regulation of liver function and glucose homeostasis. ${ }^{43-45}$ In humans, the links between the circadian clock and glucose metabolism is also clear. Epidemiological studies show that shift workers have an increased risk of developing T2D, and, in both humans and mice, polymorphisms in both CLOCK and Bmall have been implicated in the development of T2D. ${ }^{46-49}$ As it is doubtful our round-the-clock society will be changing, it will become necessary to discover ways to counteract the health problems introduced by modern conveniences and social norms. Thus, it is essential to determine whether interventions can be devised to mitigate or protect against the negative effects of circadian disruption.

While the focus of this review has been on the phenomenology and mechanisms by which disrupted circadian clocks contribute to metabolic disorder, it is also important to note that a "two-way street" exists and that metabolic factors particularly those involved in the development of obesity and/or diabetes - can also modulate circadian and sleep systems. In humans and nonhuman animals, obesity is linked to disrupted sleep and circadian rhythms. This is likely due to a variety of factors, including clinical disorders such as sleepdisordered breathing, which can lead to sleep disruption, ${ }^{50-53}$ and can be more prevalent in obese or overweight individuals. Sleep-disordered breathing is clearly related to obesity, but several studies have uncovered a relationship between sleepdisordered breathing and the insulin gene variable number of tandem repeats phenotype, ${ }^{54}$ suggesting the relationship is more complex than a simple association between the obese phenotype and a direct effect on airways. Intriguingly, there are reports that obesity in humans, even without sleep apnea, can lead to altered amounts of sleep and wake. ${ }^{55}$ Animal studies have also contributed to the findings that obesity can lead to altered circadian and sleep parameters, including a change in the amount of time spent in wake or sleep. ${ }^{56,57}$ Furthermore, genetically obese models, such as in leptin-deficient mice en-60 $^{58}$ and Zucker rats, ${ }^{61,62}$ also show disruption in the amount of sleep and sleep timing. Taken together, these findings suggest that there is likely a bidirectional relationship between sleep and circadian disruption and obesity.

\section{Environmental circadian disruption contributes to metabolic dysregulation}

While this work illustrates the proximate link between circadian timing and metabolic function, clock gene mutations and tissue-specific knockouts do not directly address the ultimate causes of circadian disruption-induced metabolic dysregulation. To explore this, it is necessary to manipulate the circadian environment (ie, the light-dark cycle) and ascertain the effects on metabolic systems. Elegant studies demonstrate that the molecular circadian clock is coupled to metabolism at the cellular level, and that circadian mutant animals develop metabolic dysregulation and obesity. That said, the physiological and cellular mechanisms translating environmental circadian disruption to increased weight gain and metabolic syndrome remain unknown. This gap limits our mechanistic understanding of the role of circadian rhythms in the development of metabolic dysregulation. Epidemiologically, the current "obesity epidemic" is correlated with a gradual decrease in sleep time and quality (reviewed by Van Cauter et al), ${ }^{63}$ and a causal link is plausible. The causes of this decrease in sleep time and quality are likely due to the significant lifestyle changes that have occurred with industrialization, modern changes in work behavior, and the advent of electric lighting. Obvious circadian disruption is found in shift workers (eg, airline crews, truck drivers, medical doctors, law enforcement, and the military). However, the general public is exposed to light late into the night (eg, electronic devices), work schedules that conflict with an individual's chronotype (endogenous circadian preference), and "social jet lag" (changes in sleep patterns from the work days to nonwork days such as weekends). ${ }^{64}$ The ramifications of this desynchronization for mental and physical health are not fully understood. However, several lines of evidence link defects in circadian timing with negative health outcomes, ${ }^{37,65}$ including obesity and diabetes. Individuals reporting poor sleep show increased incidence of diabetes and risk factors for the development of cardiovascular disease. ${ }^{63,66}$ Social jet lag has been associated with a higher BMI, ${ }^{64}$ indicating that this phenomenon is not restricted only to shift workers or individuals with repeatedly altered sleep-wake schedules. The specific mechanisms for these changes remain obscure; however, in humans a relationship between misaligned sleep and glucose homeostasis has been found, and misaligned sleep can lead to plasma glucose levels approaching those of diabetics. ${ }^{67}$ Thus, a link between environmental circadian disruption and metabolic dysregulation is evident. Investigating this link experimentally requires the use of animal models to probe connections between disruption of the circadian clock and metabolic output.

Understanding the precise mechanisms by which the master circadian clock (ie, the $\mathrm{SCN}$ ) is able to reset peripheral clocks and how such regulation is able to affect downstream 
pathways, such as glucose and lipid metabolism, has been a major focus for researchers in this area over the last decade. Animal model systems have been useful tools to unravel the complex connections between environmental stimuli, circadian rhythms (and sleep), and metabolic dysregulation. This approach is possible because circadian rhythms in physiology and behavior are both phylogenetically ancient and incredibly well conserved between species. Altering the light-dark environment of experimental animals has proven to be an elegant and simple way to begin to probe how disruption of the circadian clock by light can affect various physiological systems and brain function. One approach is to expose animals to light at inappropriate times of the day. Studies in mice show that exposure to dim light at night results in statistically significant increases in body weight without overall increases in food consumption, but, rather, shifts to more food consumed during the daytime. ${ }^{68,69}$

Since most rodents studied in the laboratory are nocturnal (eg, rats, mice, hamsters), results of these types of studies are sometimes difficult to interpret, given that light is an "inhibiting" stimulus in these species, while in humans, light is arousing. The use of diurnal or crepuscular species can help with this problem. Several findings indicate that reducing light during the day in the diurnal grass rat leads to depression-like behaviors, and related changes in neural pathways that are known to modulate emotional behaviors. ${ }^{70,71}$ Together, this work highlights the significant link between the photic environment and mental and physical health in animal models.

Another approach used by several groups relies on rapid or repeated changes in the normal light-dark cycle, inducing a kind of "internal desynchrony", perhaps more closely resembling the effects of rotating shift work or unpredictable work hours. By using a very short (7 hour) light-dark cycle, LeGates et al have shown clear effects on learning and memory, and these effects are modulated by the directly SCN-projecting melanopsin containing retinal ganglion cells. ${ }^{72}$ Karatsoreos et al used a 10-hour light-dark cycle and found that this type of circadian disruption led to atrophy of pyramidal neurons in the medial prefrontal cortex (mPFC) and an associated reduction in cognitive flexibility and altered behavior in novel environments. ${ }^{73}$ While this article was one of the first to demonstrate disruption of the circadian clock by light leads to extrahypothalamic changes in neural morphology, the authors also showed that mice in the 10-hour light-dark cycle gained more weight than controls, had elevated levels of leptin and triglycerides in their blood, and also demonstrated an increased insulin:glucose ratio, suggesting a prediabetic or diabetic state, ${ }^{73}$ clearly demonstrating that environmental circadian disruption leads to metabolic dysregulation and potential diabetic states. Intriguingly, the metabolic effects occur even though there is no difference in overall food consumption between disrupted and nondisrupted mice. This effect on glucose balance is supported by work from human studies, in which it was found that even short-term misalignment of sleep rhythms could lead to postprandial plasma glucose levels that were in the diabetic range ${ }^{67}$ The molecular and cellular mechanisms of these effects, and their anatomic pathways, are as yet unclear, but several lines of evidence point to a substantial role for circadian regulation of glucose metabolism.

While laboratory studies on altered sleep cycles and circadian timing in humans are clearly important in elucidating the specific parameters that may directly impact metabolic function, patterns of human settlement on the earth can provide an additional level of information on the link between the external environment, circadian/sleep disruption, and metabolism. High (polar) latitudes present an interesting set of challenges for all life, with extreme climate and stark changes in the photic environment based upon season. In several species, circadian adaptations to living in these temporal environments include almost constant ultradian behavioral patterns. ${ }^{74-76}$ For humans, living in polar latitudes has significant effects on several aspects of mental and physical health, including mood, sleep timing, and metabolic function. ${ }^{77-80}$ However, as discussed by Arendt, there are significant differences between resident native populations and visiting temporary populations, suggesting possible adaptive responses over the long-term, or inherited genetic differences. ${ }^{80}$ Focusing only on temporary visitors to the Arctic or Antarctic, it is clear that several physiological and behavioral markers are altered by this extreme environment, ${ }^{80}$ including energy dynamics and aerobic fitness, ${ }^{81}$ as well as melatonin, cortisol, and electrolytes ${ }^{82}$ A recent longitudinal study demonstrated that there were significant changes in body weight and body fat during the Antarctic winter, but no observed seasonal effects on food intake, activity, and aerobic fitness. ${ }^{83}$ However, circadian metabolic data are sparse. Two studies show that oral glucose tolerance was greater in March and December in the Antarctic. ${ }^{84,85}$ The mechanisms mediating these effects remain mysterious, with one study suggesting that the timing of meals may be the most salient cue in the perpetual daylight of the Arctic summer. ${ }^{86}$ However, the clear effects of circadian and sleep disruption on metabolism discussed in this review, and the fact that sleep in Antarctic visitors is disrupted but can be improved by timed exposure 
to light, ${ }^{87-89}$ suggest that at least some of the metabolic effects are mediated by circadian processes.

\section{Conclusion}

While work linking circadian function and metabolism at the cellular level is clearly bearing fruit by elegantly showing the role of the circadian clock in metabolic function even at the cellular level, determining pathways by which environmental disruption affects myriad organ systems remains an area of intense study. The "circadian-web" model $^{37}$ can be used as a good springboard to explore the many pathways by which circadian rhythms, and circadian disruption, affect such a wide array of organ systems. In this model, "peripheral oscillators" throughout the brain and body are responsible for setting "local time" in various organs and tissues, and are synchronized by numerous inputs. These inputs may include rhythms of circulating glucocorticoids, ${ }^{90,91}$ feeding, ${ }^{92}$ and body temperature. ${ }^{93}$ As such, these synchronizing pathways may serve as appropriate methods to resynchronize disrupted clocks, potentially preventing the metabolic cost incurred by chronic circadian disruption.

Since the advent of electric lighting and modern industry, humans have broken the once-tight connection between the external solar day and our daily activities. These changes have happened rapidly over the past $100-150$ years, and thus represent an incredibly fast environmental change when viewed in the context of the evolution of the circadian clock. Epidemiological evidence supports the hypothesis that changes in "circadian hygiene", such as work schedules, light exposure at night, and new societal norms in industrialized society are contributing to the rapid increase in obesity and cardiometabolic disorders such as T2D. There is a growing body of work, in both human and nonhuman animal models, that links changes in circadian light-dark cycles to physiological and psychological disorders, and more work is necessary to explore the mechanisms by which these altered cycles affect metabolic function. Elegant molecular work exploring the role of circadian clock genes at the tissue level has uncovered an important role in the development of obesity and diabetes. Investigating how environmental mediators affect the development and trajectory of dysregulated metabolic function and obesity is an important complement to the molecular and genetic work, as specific genetic mutations are less likely to be direct mediators of obesity in human populations while environmental mediators are more pertinent contributing factors. Linking findings in the fields of obesity and diabetes to other areas of research, such as aging research showing similar changes in both circadian rhythms ${ }^{94-98}$ and metabolism, ${ }^{99-101}$ will also prove fruitful, as this may provide novel synergies as well as reveal commonalities. How disruption of central and peripheral clock function (as measured by metabolic hormone and clock gene rhythms) contributes to the development of obesity and diabetes remains unknown, but probing the mechanisms by which synchronizing factors such as feeding schedules or glucocorticoid rhythms modulate circadian-driven metabolic dysregulation both in the periphery and in the brain should yield important insights.

\section{Acknowledgments}

The author acknowledges the support of Washington State University College of Veterinary Medicine Intramural Funding, and a NARSAD Young Investigator Grant from the Brain and Behavior Research Foundation.

\section{Disclosure}

The author reports no conflicts of interest in this work.

\section{References}

1. Finkelstein EA, Trogdon JG, Cohen JW, Dietz W. Annual medical spending attributable to obesity: payer-and service-specific estimates. Health Aff. 2009;28(5):w822-w831.

2. Maury E, Hong HK, Bass J. Circadian disruption in the pathogenesis of metabolic syndrome. Diabetes Metab. Epub January 14, 2014.

3. Giudice A, Crispo A, Massimiliano G, et al. Metabolic syndrome, insulin resistance, circadian disruption, antioxidants and pancreatic carcinoma: an overview. J Gastrointestin Liver Dis. 2014;23(1):73-77.

4. Gamble KL, Berry R, Frank SJ, Young ME. Circadian clock control of endocrine factors. Nat Rev Endocrinol. 2014;10(8):466-475.

5. Depner CM, Stothard ER, Wright KP Jr. Metabolic consequences of sleep and circadian disorders. Curr Diab Rep. 2014;14(7):507.

6. Yurgel ME, Masek P, DiAngelo J, Keene AC. Genetic dissection of sleep-metabolism interactions in the fruit fly. J Comp Physiol A Neuroethol Sens Neural Behav Physiol. Epub September 19, 2014.

7. Kalsbeek A, Kreier F, Fliers E, Sauerwein HP, Romijn JA, Buijs RM. Circadian control of metabolism by the SCN. Endocrinology. 2007; 148(12):5635-5639.

8. Karatsoreos IN, Silver R. Minireview: the neuroendocrinology of the suprachiasmatic nucleus as a conductor of body time in mammals. Endocrinology. 2007;148(12):5640-5647.

9. Butler MP, Kriegsfeld LJ, Silver R. Circadian regualtion of endocrine functions. In: Pfaff D, Arnold A, Etgen A, Fahrbach S, Rubin R, editors. Hormones, Brain and Behavior. Vol 1. 2nd ed. San Diego, CA: Academic Press; 2009:473-505.

10. Bell-Pedersen D, Cassone VM, Earnest DJ, et al. Circadian rhythms from multiple oscillators: lessons from diverse organisms. Nat rev Genet. 2005;6(7):544-556.

11. Stephan FK, Zucker I. Circadian rhythms in drinking behavior and locomotor activity of rats are eliminated by hypothalamic lesions. Proc Natl Acad Sci U S A. 1972;69(6):1583-1586.

12. Moore RY, Eichler VB. Loss of a circadian adrenal corticosterone rhythm following suprachiasmatic lesions in the rat. Brain Res. 1972;42(1):201-206.

13. LeSauter J, Lehman MN, Silver R. Restoration of circadian rhythmicity by transplants of SCN "micropunches". J Biol Rhythms. 1996;11(2): 163-171. 
14. Ralph MR, Foster RG, Davis FC, Menaker M. Transplanted suprachiasmatic nucleus determines circadian period. Science. 1990;247(4945): 975-978.

15. Silver R, Lehman MN, Gibson M, Gladstone WR, Bittman EL. Dispersed cell suspensions of fetal SCN restore circadian rhythmicity in SCN-lesioned adult hamsters. Brain Res. 1990;525(1):45-58.

16. Robinson I, Reddy AB. Molecular mechanisms of the circadian clockwork in mammals. FEBS lett. 2014;588(15):2477-2483.

17. Lim C, Allada R. Emerging roles for post-transcriptional regulation in circadian clocks. Nat Neurosci. 2013;16(11):1544-1550.

18. Guillaumond F, Dardente H, Giguere V, Cermakian N. Differential control of Bmall circadian transcription by REV-ERB and ROR nuclear receptors. J Biol Rhythms. 2005;20(5):391-403.

19. Stevens RG, Brainard GC, Blask DE, Lockley SW, Motta ME. Adverse health effects of nighttime lighting: comments on American Medical Association policy statement. Am J Prev Med. 2013;45(3): 343-346.

20. Bass J, Takahashi JS. Circadian integration of metabolism and energetics. Science. 2010;330(6009):1349-1354.

21. Marcheva B, Ramsey KM, Buhr ED, et al. Disruption of the clock components CLOCK and BMAL1 leads to hypoinsulinaemia and diabetes. Nature. 2010;466(7306):627-631.

22. Bass J. Circadian topology of metabolism. Nature. 2012;491(7424): 348-356.

23. Tamashiro KL, Sakai RR, Shively CA, Karatsoreos IN, Reagan LP. Chronic stress, metabolism, and metabolic syndrome. Stress. 2011;14(5):468-474.

24. Laposky AD, Bass J, Kohsaka A, Turek FW. Sleep and circadian rhythms: key components in the regulation of energy metabolism. FEBS Lett. 2008;582(1):142-151.

25. Bartness TJ. Photoperiod, sex, gonadal steroids, and housing density affect body fat in hamsters. Physiol Behav. 1996;60(2):517-529.

26. Bartness TJ, Song CK, Demas GE. SCN efferents to peripheral tissues: implications for biological rhythms. J Biol Rhythms. 2001;16(3):196-204.

27. Karatsoreos IN. Effects of circadian disruption on mental and physical health. Curr Neurol Neurosci Rep. 2012;12(2):218-225.

28. McClung CA. How might circadian rhythms control mood? Let me count the ways. Biol Psychiatry. 2013;74(4):242-249.

29. Lowden A, Moreno C, Holmback U, Lennernas M, Tucker P. Eating and shift work-effects on habits, metabolism and performance. Scand J Work Environ Health. 2010;36(2):150-162.

30. Turek FW, Joshu C, Kohsaka A, et al. Obesity and metabolic syndrome in circadian Clock mutant mice. Science. 2005;308(5724):1043-1045.

31. Shi SQ, Ansari TS, McGuinness OP, Wasserman DH, Johnson CH Circadian disruption leads to insulin resistance and obesity. Curr Biol. 2013;23(5):372-381

32. Qian X, Droste SK, Lightman SL, Reul JM, Linthorst AC. Circadian and ultradian rhythms of free glucocorticoid hormone are highly synchronized between the blood, the subcutaneous tissue, and the brain. Endocrinology. 153(9):4346-4353.

33. Rudic RD, McNamara P, Curtis AM, et al. BMAL1 and CLOCK, two essential components of the circadian clock, are involved in glucose homeostasis. PLoS Biol. 2004;2(11):e377.

34. Walker JJ, Spiga F, Waite E, et al. The origin of glucocorticoid hormone oscillations. PLoS Biol. 2012;10(6):e1001341.

35. Zani F, Breasson L, Becattini B, et al. PER2 promotes glucose storage to liver glycogen during feeding and acute fasting by inducing Gys2 PTG and G L expression. Mol Metab. 2013;2(3):292-305.

36. Reppert SM, Weaver DR. Coordination of circadian timing in mammals. Nature. 2002;418(6901):935-941.

37. Hastings MH, Reddy AB, Maywood ES. A clockwork web: circadian timing in brain and periphery, in health and disease. Nat Rev Neurosci. 2003;4(8):649-661.

38. Akhtar RA, Reddy AB, Maywood ES, et al. Circadian cycling of the mouse liver transcriptome, as revealed by cDNA microarray, is driven by the suprachiasmatic nucleus. Curr Biol. 2002;12(7):540-550.
39. Reddy AB, Karp NA, Maywood ES, et al. Circadian orchestration of the hepatic proteome. Curr Biol. 2006;16(11):1107-1115.

40. Eckel-Mahan KL, Patel VR, Mohney RP, Vignola KS, Baldi P, Sassone-Corsi P. Coordination of the transcriptome and metabolome by the circadian clock. Proc Natl Acad Sci U S A. 2012;109(14): 5541-5546.

41. Eckel-Mahan K, Sassone-Corsi P. Metabolism and the circadian clock converge. Physiol Rev. 2013;93(1):107-135.

42. Kalsbeek A, la Fleur S, Fliers E. Circadian control of glucose metabolism. Mol Metab. 2014;3(4):372-383.

43. Kalsbeek A, Yi CX, La Fleur SE, Fliers E. The hypothalamic clock and its control of glucose homeostasis. Trends Endocrinol Metab. 2010;21(7):402-410.

44. Buijs RM, Wortel J, Van Heerikhuize JJ, et al. Anatomical and functional demonstration of a multisynaptic suprachiasmatic nucleus adrenal (cortex) pathway. Eur J Neurosci. 1999;11(5):1535-1544.

45. Cailotto C, La Fleur SE, Van Heijningen C, et al. The suprachiasmatic nucleus controls the daily variation of plasma glucose via the autonomic output to the liver: are the clock genes involved? Eur J Neurosci. 2005;22(10):2531-2540.

46. Suwazono Y, Dochi M, Sakata K, et al. A longitudinal study on the effect of shift work on weight gain in male Japanese workers. Obesity (Silver Spring). 2008;16(8):1887-1893.

47. Zhao Y, Zhang Y, Zhou M, Wang S, Hua Z, Zhang J. Loss of mPer2 increases plasma insulin levels by enhanced glucose-stimulated insulin secretion and impaired insulin clearance in mice. FEBS lett. 2012;586(9):1306-1311.

48. Kroenke CH, Spiegelman D, Manson J, Schernhammer ES, Colditz GA, Kawachi I. Work characteristics and incidence of type 2 diabetes in women. Am J Epidemiol. 2007;165(2):175-183.

49. Barclay JL, Shostak A, Leliavski A, et al. High-fat diet-induced hyperinsulinemia and tissue-specific insulin resistance in Cry-deficient mice. Am J Physiol Endocrinol Metab. 2013;304(10):E1053-E1063.

50. Yang JS, Nicholas CL, Nixon GM, et al. Determining sleep quality in children with sleep disordered breathing: EEG spectral analysis compared with conventional polysomnography. Sleep. 2010;33(9): 1165-1172.

51. Kapur VK, Baldwin CM, Resnick HE, Gottlieb DJ, Nieto FJ. Sleepiness in patients with moderate to severe sleep-disordered breathing. Sleep 2005;28(4):472-477.

52. Chami HA, Baldwin CM, Silverman A, et al. Sleepiness, quality of life, and sleep maintenance in REM versus non-REM sleep-disordered breathing. Am J Respir Crit Care Med. 2010;181(9):997-1002.

53. Seetho IW, Wilding JP. Sleep-disordered breathing, type 2 diabetes and the metabolic syndrome. Chron Respir Dis. Epub October 3, 2014.

54. Carotenuto M, Santoro N, Grandone A, et al. The insulin gene variable number of tandemrepeats (INS VNTR) genotype and sleep disordered breathing in childhood obesity. $J$ Endocrinol Invest. 2009;32(9):752-755.

55. Vgontzas AN, Bixler EO, Tan TL, Kantner D, Martin LF, Kales A. Obesity without sleep apnea is associated with daytime sleepiness. Arch Intern Med. 1998;158(12):1333-1337.

56. Luppi M, Cerri M, Martelli D, et al. Waking and sleeping in the rat made obese through a high-fat hypercaloric diet. Behav Brain Res. 2014;258:145-152.

57. Jenkins JB, Omori T, Guan Z, Vgontzas AN, Bixler EO, Fang J. Sleep is increased in mice with obesity induced by high-fat food. Physiol Behav. 2006;87(2):255-262.

58. Silvani A, Bastianini S, Berteotti C, et al. Sleep modulates hypertension in leptin-deficient obese mice. Hypertension. 2009;53(2):251-255.

59. Laposky AD, Shelton J, Bass J, Dugovic C, Perrino N, Turek FW. Altered sleep regulation in leptin-deficient mice. Am J Physiol Regul Integr Comp Physiol. 2006;290(4):R894-R903.

60. Laposky AD, Bradley MA, Williams DL, Bass J, Turek FW. Sleep-wake regulation is altered in leptin-resistant $(\mathrm{db} / \mathrm{db})$ genetically obese and diabetic mice. Am J Physiol Regul Integr Comp Physiol. Dec 2008;295(6):R2059-R2066. 
61. Megirian D, Dmochowski J, Farkas GA. Mechanism controlling sleep organization of the obese Zucker rats. J Appl Physiol. 1998;84(1):253-256.

62. Danguir J. Sleep patterns in the genetically obese Zucker rat: effect of acarbose treatment. Am J Physiol. 1989;256(1, pt 2):R281-R283.

63. Van Cauter E, Spiegel K, Tasali E, Leproult R. Metabolic consequences of sleep and sleep loss. Sleep Med. 2008;9(Suppl 1):S23-S28.

64. Roenneberg T, Allebrandt KV, Merrow M, Vetter C. Social jetlag and obesity. Curr Biol. 2012;22(10):939-943.

65. Bechtold DA, Gibbs JE, Loudon AS. Circadian dysfunction in disease. Trends Pharmacol Sci. 2010;31(5):191-198.

66. Spiegel K, Tasali E, Leproult R, Van Cauter E. Effects of poor and short sleep on glucose metabolism and obesity risk. Nat Rev Endocrinol. 2009;5(5):253-261.

67. Scheer FA, Hilton MF, Mantzoros CS, Shea SA. Adverse metabolic and cardiovascular consequences of circadian misalignment. Proc Natl Acad Sci U S A. 2009;106(11):4453-4458.

68. Fonken LK, Workman JL, Walton JC, et al. Light at night increases body mass by shifting the time of food intake. Proc Natl Acad Sci USA. 2010;107(43):18664-18669.

69. Fonken LK, Lieberman RA, Weil ZM, Nelson RJ. Dim light at night exaggerates weight gain and inflammation associated with a high-fat diet in male mice. Endocrinology. 2013;154(10):3817-3825.

70. Leach G, Adidharma W, Yan L. Depression-like responses induced by daytime light deficiency in the diurnal grass rat (Arvicanthis niloticus). PLoS One. 2013;8(2):e57115.

71. Leach G, Ramanathan C, Langel J, Yan L. Responses of brain and behavior to changing day-length in the diurnal grass rat (Arvicanthis niloticus). Neuroscience. 2013;234:31-39.

72. LeGates TA, Altimus $\mathrm{CM}$, Wang $\mathrm{H}$, et al. Aberrant light directly impairs mood and learning through melanopsin-expressing neurons. Nature. 2012;491(7425):594-598

73. Karatsoreos IN, Bhagat S, Bloss EB, Morrison JH, McEwen BS. Disruption of circadian clocks has ramifications for metabolism, brain, and behavior. Proc Natl Acad Sci U S A. 2011;108(4): $1657-1662$.

74. van Oort BE, Tyler NJ, Gerkema MP, Folkow L, Blix AS, Stokkan KA. Circadian organization in reindeer. Nature. 2005;438(7071): 1095-1096.

75. Kronfeld-Schor N, Bloch G, Schwartz WJ. Animal clocks: when science meets nature. Proc Biol Sci. 2013;280(1765):20131354.

76. Bloch G, Barnes BM, Gerkema MP, Helm B. Animal activity around the clock with no overt circadian rhythms: patterns, mechanisms and adaptive value. Proc Biol Sci. 2013;280(1765):20130019.

77. Panin LE. Human homeostasis in high-latitude environment. Alaska Med. 2007;49(Suppl 2):25-28.

78. Hasnulin PV, Seliatitskaya VG. Metabolism, endocrine status, and allergy in the extreme north. Int J Circumpolar Health. 2001;60(4): 593-603.

79. Friborg O, Rosenvinge JH, Wynn R, Gradisar M. Sleep timing, chronotype, mood, and behavior at an Arctic latitude (69 N). Sleep Med. 2014;15(7):798-807.

80. Arendt J. Biological rhythms during residence in polar regions. Chronobiol Int. 2012;29(4):379-394.

81. Simpson A. The effect of Antarctic residence on energy dynamics and aerobic fitness. Int J Circumpolar Health. 2010;69(3):220-235.

82. Kennaway DJ, Van Dorp CF. Free-running rhythms of melatonin, cortisol, electrolytes, and sleep in humans in Antarctica. Am J Physiol. 1991;260(6, pt 2):R1137-R1144
83. Simpson A, Maynard V. A longitudinal study of the effect of Antarctic residence on energy dynamics and aerobic fitness. Int J Circumpolar Health. 2012;71:17227.

84. Campbell IT, Jarrett RJ, Rutland P, Stimmler L. The plasma insulin and growth hormone response to oral glucose: diurnal and seasonal observations in the Antarctic. Diabetologia. 1975;11(2):147-150.

85. Campbell IT, Jarrett RJ, Keen H. Diurnal and seasonal variation in oral glucose tolerance: studies in the Antarctic. Diabetologia. 1975;11(2):139-145.

86. Biali S, Jones PJ, Pederson RA, Iqbal I, Suedfeld P. Influence of a perpetual-daylight Arctic environment on periodicity in human cholesterol synthesis. Arctic Med Res. 1995;54(3):134-144.

87. Corbett RW, Middleton B, Arendt J. An hour of bright white light in the early morning improves performance and advances sleep and circadian phase during the Antarctic winter. Neurosci Lett. 2012;525(2):146-151.

88. Mottram V, Middleton B, Williams P, Arendt J. The impact of bright artificial white and 'blue-enriched' light on sleep and circadian phase during the polar winter. $J$ Sleep Res. 2011;20(1, pt 2):154-161.

89. Broadway J, Arendt J, Folkard S. Bright light phase shifts the human melatonin rhythm during the Antarctic winter. Neurosci Lett. 1987;79(1-2):185-189.

90. Balsalobre A. Clock genes in mammalian peripheral tissues. Cell Tissue Res. 2002;309(1):193-199.

91. Balsalobre A, Brown SA, Marcacci L, et al. Resetting of circadian time in peripheral tissues by glucocorticoid signaling. Science. 2000;289(5488):2344-2347.

92. Mendoza J, Graff C, Dardente H, Pevet P, Challet E. Feeding cues alter clock gene oscillations and photic responses in the suprachiasmatic nuclei of mice exposed to a light/dark cycle. J Neurosci. 2005;25(6):1514-1522.

93. Saini C, Morf J, Stratmann M, Gos P, Schibler U. Simulated body temperature rhythms reveal the phase-shifting behavior and plasticity of mammalian circadian oscillators. Genes Dev. 2012;26(6):567-580.

94. Yamazaki S, Straume M, Tei H, Sakaki Y, Menaker M, Block GD. Effects of aging on central and peripheral mammalian clocks. Proc Natl Acad Sci U S A. 2002;99(16):10801-10806.

95. Cain SW, Karatsoreos I, Gautam N, et al. Blunted cortisol rhythm is associated with learning impairment in aged hamsters. Physiol Behav. 2004;82(2-3):339-344.

96. Oosterman JM, van Someren EJ, Vogels RL, Van Harten B, Scherder EJ. Fragmentation of the rest-activity rhythm correlates with age-related cognitive deficits. J Sleep Res. 2009;18(1):129-135.

97. Duncan MJ, Smith JT, Franklin KM, et al. Effects of aging and genotype on circadian rhythms, sleep, and clock gene expression in APPXPS1 knock-in mice, a model for Alzheimer's disease. Exp Neurol. 2012;236(2):249-258.

98. Duncan MJ, Prochot JR, Cook DH, Tyler Smith J, Franklin KM. Influence of aging on Bmal1 and Per2 expression in extra-SCN oscillators in hamster brain. Brain Res. 2013;1491:44-53.

99. Mattson MP. Energy intake and exercise as determinants of brain health and vulnerability to injury and disease. Cell Metab. 2012;16(6):706-722.

100. Michalakis K, Goulis DG, Vazaiou A, Mintziori G, Polymeris A, Abrahamian-Michalakis A. Obesity in the ageing man. Metab: Clin Exp. 2013;62(10):1341-1349.

101. Newgard CB, Pessin JE. Recent progress in metabolic signaling pathways regulating aging and life span. $J$ Gerontol A Biol Sci Med Sci. 2014;69(Suppl 1):S21-S27. 
ChronoPhysiology and Therapy

\section{Publish your work in this journal}

ChronoPhysiology and Therapy is an international, peer-reviewed, open access journal focusing on research into the cyclic variations and rhythmicity in physiological processes in the body and the research and development and optimal timing of administration of therapeutic targets to achieve improved outcomes and quality of life for the patient. The

management system is completely online and includes a very quick and fair peer-review system. Visit http://www.dovepress.com/ testimonials.php to read real quotes from published authors.

Submit your manuscript here: http://www.dovepress.com/chronophysiology-and-therapy-journal 